\title{
PENGARUH DALAM PROSES KEPERAWATAN TERHADAP DOKUMENTASI ASUHAN KEPERAWATAN DI RUMAH SAKIT
}

\author{
Nadia Febriani Br. Barus
}

Nadiafebriani001@gmail.com

\section{Latar Belakang}

Tumbuhnya motivasi perawat dipicu dengan salah satunya pelaksanaan dokumentasi keperawatan. Semakin tinggi motivasi perawat apabila semakin baik pelaksanaan dokumentasi keperawatan. Pelaksanaan dokumentasi keperawatan merupakan salah satu terbentuknya motivasi perawat. Tujuannya untuk mengidentifikasi apakah ada Hubungan Motivasi Perawat Dengan Pelaksanaan proses keperawatan dalam Dokumentasi asuhan Keperawatan di rumah sakit. Keperawatan di Indonesia saat ini masih dalam suatu proses profesionalisasi yaitu terjadinya suatu perubahan dan perkembangan karakteristik sesuai tuntutan secara global dan lokal / otonomi. Untuk mewujudkannya maka perawat Indonesia harus mampu memberikan asuhan keperawatan secara profesional kepada klien dan berpartisipasi aktif dalam pembangunan bangsa dan negara. Keperawatan adalah ilmu dan kiat yang berkenaan dengan masalahmasalah fisik, psikologi, sosiologis, budaya dan spiritual dari individu. Ilmu keperawatan didasarkan atas kerangka teori yang luas, kiatnya tergantung pada ketrampilan merawat dan kemampuan perawat secara individual. Pentingnya perawat dalam sistem perawatan kesehatan telah dikenal dalam banyak hal yang positip, dan profesi keperawatan itu sendiri sedang menyatakan kebutuhan untuk para praktisinya agar menjadi profesional dan bertanggung jawab. Pelayanan keperawatan dilakukan dalam upaya meningkatkan derajat kesehatan, mencegah penyakit, penyembuhan, pemulihan serta pemeliharaan kesehatan dengan penekanan pada upaya pelayanan kesehatan utama untuk memungkinkan setiap penduduk mencapai kemampuan hidup sehat dan produktif. Dokumentasi keperawatan sangat penting bagi perawat dalam memberikan asuhan keperawatan arena pelayanan keperawatan yang diberikan pada klien membutuhkan catatan dan pelaporan yang dapat digunakan sebagai tanggung jawab dan tanggung gugat dari berbagai kemungkinan masalah yang dialami klien baik masalah kepuasan maupun ketidakpuasan terhadap pelayanan yang diberikan dalam asuhan keperawatan. Proses keperawatan sebagai alat bagi perawat untuk melaksanakan asuhan keperawatan yang dilakukan pada pasien memiliki arti penting bagi kedua belah pihak yaitu perawat dan klien. Sebagai seorang perawat proses keperawatan dapat digunakan sebagai pedoman dalam pemecahan masalah klien, dapat menunjukkan profesi yang memiliki 
profesionalitas yang tinggi, serta dapat memberikan kebebasan kepada klien untuk mendapatkan pelayanan yang cukup sesuai dengan kebutuhannya, sehingga dapat dirasakan manfaatnya baik dari perawat maupun klien, manfaat tersebut antara lain dapat meningkatkan kemandirian pada perawat dalam melaksanakan tugasnya karena didalam proses keperawatan.

\section{METODE}

dalam pengaruh proses keperawatan terhadap dokumentasi asuhan keperawatan di rumah sakit terdapat metode ilmiah keperawatan yang berupa langkah-langkah proses keperawatan, akan dapat meningkatkan kepercayaan diri perawat dalam melaksanakan tugas, karena klien akan merasakan kepuasan setelah dilakukan asuhan keperawatan dengan pendekatan proses keperawatan, akan dapat selalu meningkatkan kemampuan intelektual dan teknikal dalam tindakan keperawatan karena melalui proses keperawatan dituntut mampu memecahkan masalah yang baru sesuai dengan masalah yang dialami klien, sehingga akan timbul perasaan akan kepuasan kerja. Dengan proses keperawatan, rasa tanggung jawab dan tanggung gugat bagi perawat itu dapat dimiliki dan dapat digunakan dalam tindakan-tindakan yang merugikan atau menghindari adanya tindakan yang legal.

\section{HASIL}

Jadi hasil dari proses kepererawatan dalam Pengkajian adalah tahap awal dari proses keperawatan dan merupakan proses yang sistematis dalam pengumpulan data dari berbagai sumber data untuk mengevaluasi dan mengidentifikasi status kesehatan pasien. Pengkajian adalah pendekatan sistematis untuk mengumpulkan data dan menganalisanya. Pengkajian adalah pemikiran dasar dari proses keperawatan yang bertujuan untuk mengumpulkan informasi atau data tentang pasien, agar dapat mengidentifikasi, mengenali masalah-masalah, kebutuhan kesehatan dan keperawatan pasien, baik fisik, mental, sosial dan lingkungan peningkatan kualitas pendokumentasian asuhan keperawatan dapat dilakukan melalui pelatihan-pelatihan. Lebih lanjut Lees (2010) menjelaskan bahwa peningkatan pengetahuan atau pemahaman yang diperoleh melalui pelatihan akan mendukung pendokumentasian yang lebih lengkap. Penelitian yang dilakukan Tanasale (2003) juga menunjukkan bahwa peningkatan pengetahuan melalui pelatihan berkorelasi dengan peningkatan ketepatan pendokumentasian dan kinerja perawat. Dokumentasi asuhan keperawatanmencakup pernyataan dan pelaporan tentang pengkajian (pengumpulan data), diagnosis keperawatan, rencana tindakan keperawatan, tindakan dan evaluasi keperawatan.Dokumentasi yang efektif menjamin kesinambungan pelayanan, menghemat waktu, dan meminimalisasi resiko kesalahan (Potter \& Perry, 2009).Dokumentasi asuhan keperawatan yang baik dan berkualitas haruslah akurat, 
lengkap dan sesuai standar. Apabila asuhan keperawatan tidak didokumentasikan dengan akurat dan lengkap maka sulit untuk membuktikan bahwa asuhan keperawatan telah dilakukan dengan benar (Hidayat, 2004). Pendokumentasian asuhan keperawatan merupakan suatu proses yang harus dilaksanakan oleh perawat pelaksana sebagai bagian dari standar kerja yang telah ditetapkan model pendokumentasian yang lebih sederhana namun telah disesuaikan dengan standar. Model ini memudahkan perawat puskesmas karena menggunakan sistem checklist mulai dari pengkajian sampai dengan evaluasi. Dilengkapi dengan booklet pendidikan kesehatan terkait dengan masalah kesehatan yang dialami keluarga, maka apa yang disampaikan perawat dapat dipertanggungjawabkan secara keilmuan. Sebagai langkah awal, model ini dapat

mengkondisikan perawat untuk bekerja sesuai standar. Sayangnya belum ada standard pendidikan kesehatan terkait masalah kesehatan keluarga di puskesmas sehingga perlu adanya tim yang dapat menindaklanjuti.

\section{PEMBAHASAN}

Sebelum menyusun suatu asuhan keperawatan yang baik, kita harusmemahami langkah langkah dari proses keperawatan. Proses perawatanmerupakan suatu metode bagi perawat untuk Memberikan asuihan keperawatankepada klien. Beberapa pengertian proses kaparawatan adalah sebagai berikut. Suatu metoda pemberian asuhan keperawatan yang sistematis dan rasional (Kozier,1991). Metoda pemberian asuhan keperawatan yang terorganisir dan sistematis,berfokus pada respon yang unik dari individu terhadap masalah kesehatan yangactual dan potensial (Rosalinda,1986). Suatu aktifitas yang dinamika danberkelanjutan yang meliputi interaksi perawat klien dan proses pemecahan masalah(Schultz dan Videbeck). Proses keperawatan bukan hanya sekedar pendekatan sistematik danterorganisir melalui enam langkah dalam mengenali masalah-masalah klien, namunmerupakan suatu metode pemecahan masalah baik secara episodic maupun secaralinier. Kemudian dapat dirumuskan diagnosa keparawatannya, dan cara pemecahanmasalah.PENGERTIAN PROSES KEPERAWATAN Banyak pakar telah merumuskan definisi dari proses keperawatan (Weitzel,Marriner, Murray, Yura, Herber, dll). Secara umum dapat dikatakan bahwa proseskeperawatan adalah metode pengorganisasian yang sistematis, dalam melakuanasuhan keperawatan pada individu, kelompok dan masyarakat yang berfokus padaidentifikasi dan pemecahan masalah dari respn pasien terhadap penyakitnya(Tarwoto \& Wartonah, 2004).Proses keperawatan adalah : Suatu pendekatan sistematis untuk mengenal masalah-masalah pasien danmencarikan alternatif pemecahan masalah dalam memenuhi kebutuhan-kebutuhanpasien.Merupakan proses pemecahan masalah yang dinamis dalam memperbaiki danmeningkatkan kesehatan pasien sampai ke tahap maksimum. Merupakan pendekatan ilmiah Terdiri dari 4 tahap : pengkajian, 
perencanaan, pelaksanaan dan evaluasi. Atau, adapula yang menterjemahkannya ke dalam 5 tahap : pengkajian, perumusan diagnosiskeperawatan, perencanaan, pelaksanaan dan evaluasi. Pelayanan keperawatan merupakan bagian integral dari pelayanan kesehatan yang bisa menjadi tolak ukur keberhasilan dalam pencapaian tujuan suatu rumah sakit. Kualitas pelayanan keperawatan berjalan dengan baik apabila proses keperawatan yang dilaksanakan terstruktur dengan baik (Farlinda, 2011). Kualitas pelayanan yang baik akan meningkatkan kepuasan pasien dan keluarga demikian juga sebaliknya jika pasien dan keluarga tidak puas maka akan meninggalkan rumah sakit bila kualitas pelayanan buruk. Dokumentasi keperawatan merupakan aspek penting yang perlu ditingkatkan. Dokumentasi keperawatan menjadi salah satu fungsi yang paling penting dari perawat sejak zaman Florence Nightingale, sistem pelayanan kesehatan mengharuskan adanya pendokumentasian karena dapat menjamin kelangsungan perawatan, dapat berfungsi sebagai bukti hukum dari proses perawatan dan mendukung evaluasi kualitas perawatan pasien, perawat yang kurang patuh dalam pendokumentasi asuhan keperawatan akan berakibat pada rendahnya mutu kelengkapan dokumentasi asuhan keperawatan. Pendokumentasian asuhan keperawatan yang tidak dilakukan dengan lengkap dapat menurunkan mutu pelayanan keperawatan karena tidak dapat menilai sejauh mana tingkat keberhasilan asuhan keperawatan yang telah diberikan Salah satu upaya untuk meningkatkan pelayanan keperawatan yang bermutu dan profesional adalah dengan menerapkan model. asuhan keperawatan profesional metode tim yang memungkinkan perawat profesional mengatur dalam pemberian asuhan keperawatan termasuk lingkungan untuk menopang pemberian asuhan tersebut. Pengembangan model asuhan keperawatan profesional metode tim dikembangkan untuk menjawab tantangan terhadap kualitas pelayanan dan asuhan keperawatan yang dirasakan belum memuaskan. Model asuhan keperawatan profesional metode tim telah dilaksanakan di berbagai Negara termasuk rumah sakit di Indonesia. menerangkan bahwa dokumentasi keperawatan mempunyai makna yang penting yang dapat dilihat dari berbagai aspek seperti aspek hukum, kualitas pelayanan, komunikasi, keuangan, pendidikan, penelitian, dan akreditasi. Pengisian dokumentasi keperawatan yang tidak memenuhi standar dapat mengakibatkan terjadinya kesalahan diagnosa dan pemberian tindakan yang tidak tepat kepada pasien. Selain itu dokumentasi keperawatan yaitun merupakan bukti hukum yang dapat dipergunakan untuk mendukung perawat ketika menghadapi permasalahan hokum. erupakan tahap awal proses keperawatan danmerupakan suatu proses yang sistematis dalam pengumpulan data dariberbagai sumber data untuk mengevaluasi dan mengidentifikasi statuskesehatan klien. Tahap pengkajian merupakan pemikiran dasar dalam memberikan asuhankeperawatan sesuai dengan kebutuhan individu. Pengkajian yang lengkap, akurat,sesuai kenyataan, kebenaran data sangat penting untuk merumuskan suatudiagnosa keperawatan dan dalam memberikan asuhan keperawatan sesuai denganrespon individu. Data Dasar adalah kumpulan data yang berisikan mengenai statuskesehatan klien, kemampuan klien untuk mengelola kesehatan terhadap dirinyasendiri, 
dan hasil konsultasi dari medis atau profesi kesehatan lainnya. Data Fokus adalah data tentang perubahan-perubahan atau respon klienterhadap kesehatan dan masalah kesehatannya serta hal-hal yang mencakuptindakan yang dilaksanakan terhadap klien. Fokus Pengkajian Keperawatan Pengkajian keperawatan tidak samadengan pengkajian medis. Pengkajian medis difokuskan pada keadaan patologis,sedangkan pengkajian keperawatan ditujukan pada respon klien terhadap masalah-masalah kesehatan yang berhubungan dengan pemenuhan kebutuhan dasarmanusia. Misalnya dapatkah klien melakukan aktivitas sehari-hari, sehingga fokuspengkajian klien adalah respon klien yang nyata maupun potensial terhadapmasalahmasalah aktifitas harian. Pulta (Pengumpulan Data) Pengumpulan data adalah pengumpulaninformasi tentang klien yang dilakukan secara sistematis untuk menentukanmasalah-masalah, serta kebutuhan-kebutuhan keperawatan dan kesehatan klien.

Pengumpulan informasi merupakan tahap awal dalam proses keperawatan.Dari informasi yang terkumpul, didapatkan data dasar tentang masalah-masalahyang dihadapi klien. Selanjutnya data dasar tersebut digunakan untuk menentukandiagnosis keperawatan, merencanakan asuhan keperawatan, serta tindakankeperawatan untuk mengatasi masalah-masalah klien. Proses keperawatan adalah suatu pendekatan untuk pemecahan masalah yang memampukan perawat untuk mengatur dan memberikan asuhan keperawatan. Proses keperawatan mengandung elemen berpikir kritis yang memungkinkan perawat membuat penilaian dan melakukan tindakan berdasarkan nalar. Proses adalah serangkaian tahapan atau komponen yang mengarah pada pencapaian tujuan. UJUAN RPOSES KEPERAWATAN Tujuan dari penerapan proses keperawatan pada tatanan pelayanan kesehatan adalah: a. Untuk mempraktekkan suatu metoda pemecahan masalah dalam praktek keperawatan. b. Sebagai standar untuk praktek keperawatan. c. Untuk memperoleh suatu metoda yang baku, sistematis, rasional,serta ilmiah dalammemberikan asuhan keperawatan. d. Untuk memperoleh suatu metoda dalam memberikan asuhan keperawatan yang dapatdigunakan dalam segala situasi sepanjang siklus kehidupan. e. Untuk memperoleh hasil asuhan keperawatan yang bermutu.

\section{PENUTUP}

Proses keperawatan merupakan suatu kegiatan yang terorganisir denganmenggunakan metode yang sistematis dalam memberikan ASKEP kepadaindividu,kelompok,keluarga dan masyarakat terhadap masalah kesehatan yangdialami. Proses keperawatan terdiri dari 5 tahap yaitu: Pengkajian, Diognasa,Perencanaan, Pelaksanaan dan Evaluasi. Tahap-tahap dalam proses keperawatansaling berkesinambungan dan tidak dapat di pisahkan satu sama lain 


\section{DAFTAR PUSTAKA}

1. Simamora, R. H. (2019). Development of Guidelines for Applying appropriate Patient Identification to Achieve Patient Safety Goal

INC2019 12th International Nursing Conference. 2019.10455 - 455 (1 pages) UCI(KEPA) : 1410-ECN-0101-2019-512-001224337

2. Simamora. R. H. (2008) The correlation of ward chief's giving direction and command and the performance of on-duty nurses at Jember dr. Subandi general hospital inpatient wards. jurnal Administrasi dan Kebijakan Kesehatan, (https://fkm.unair.ac.id/jurnaladministr)

3. Fitri yeni. 2014.Pengaruh Pelatihan Proses Keperawatan terhadap Dokumentasi Asuhan Keperawatan di Puskesmas Kabupaten Agam Propinsi Sumatera Barat. NERS JURNAL KEPERAWATAN. Volume 10, No 1, Hal: 21-27

4. Mohamad Kasim \& Muh. Abdurrouf.2016. PENINGKATAN KUALITAS PELAYANAN DAN PENDOKUMENTASIAN ASUHAN KEPERAWATAN DENGAN METODE TIM (THE INCREASING SERVICE QUALITY AND NURSING CARE DOCUMENTATION BY TEAM METHOD IMPLEMENTATION). NurseLine Journal Vol. 1 No.1.hal 63-71

5. Supratti \& Ashriady.2016.PENDOKUMENTASIAN STANDAR ASUHAN KEPERAWATAN DI RUMAH SAKIT UMUM DAERAH MAMUJU, INDONESIA. Jurnal kesehatan manarung. Vol 2 no1.hal $44-50$

6. Anissa Wahyu Lestari. 2019. Hubungan Motivasi Perawat dengan Pelaksanaan Dokumentasi Keperawatan di Rumah Sakit Islam Sultan Agung Semarang.Relationship of Nurse Motivation with Implementation of Nursing Documentation in Hospital Sultan Agung Islamic Semarang. Prosiding SEMINAR NASIONAL MAHASISWA Universitas Islam Sultan Agung Semarang. Vol 4 no 1. Hal 28-38.

7. Weni Lidya Hendayani. 2019. Hubungan Motivasi Perawat Dengan Pendokumentasian Asuhan Keperawatan Di Ruangan Rawat Inap Interne RSUD Kota Padang Panjang Relation About Motivation Of Nurse And Documentasion Of Nursing Care At Internal Room On Rsud Padang Panjang In Padang Panjang. Vol. XIII No.5. hal 202-209. 
8. Mohammad Iqbal Bumulo, Hendro Bidjuni \& Jeavery Bawotong. 2017.PENGARUH MANAJEMEN MODEL ASUHAN KEPERAWATAN PROFESIONAL TIM TERHADAP KUALITAS PELAYANAN KEPERAWATAN DI BANGSAL PRIA RSUD DATOE BINANGKANG KABUPATEN BOLAANG MONGONDOW. e-Jurnal Keperawatan (e-Kp) Volume 5 Nomor 2. Hal 1-4.

9. Muhammad Purnomo \& Hilal Ariadi. 2017. Analisis Dokumentasi Keperawatan dengan Instrumen A di Ruang Arafah Rumah Sakit Habibullah Gabus Grobogan Tahun 2016. Jurnal SMART Keperawatan Sekolah Tinggi Ilmu Kesehatan (STIKes) Karya Husada Semarang.VOL.4 NO.1. hal 38-49.

10. Fici Yuliana Sari. 2019. ANALISIS PENERAPAN PROSES ASUHAN KEPERAWATAN TERKAIT MANAJEMEN NYERI TERHADAP KEPUASAN PASIEN DI RUMAH SAKIT UNIVERSITAS TANJUNGPURA (Analysi Of Implementation Of Nursing Process Related To Pain Management With Patient Satisfaction In Tanjungpura University Hospital).vol 04 n0 1. Hal 1-10.

11. Kristiana Prasetia, Elisabeth Erawati \& Hersa Donantya.2020.PERBEDAAN VOLUME RESIDU LAMBUNG BERDASARKAN METODE PEMBERIAN NUTRISI ENTERAL BOLUS DAN INTERMITTENT PADA PASIEN STROKE DI RUMAH SAKIT ST. ELISABETH SEMARANG. Jurnal Manajemen Asuhan Keperawatan Vol. 4 No. 2, Halaman 70 - 78.

12. Muryani, Endang Pertiwiwati, Herry Setiawan.2019. KUALITAS PENDOKUMENTASIAN ASUHAN KEPERAWATAN DI RUANG RAWAT INAP (Studi di RSUD Kalimantan Tengah). Nerspedia, vol 2(1). Hal 27-32 
